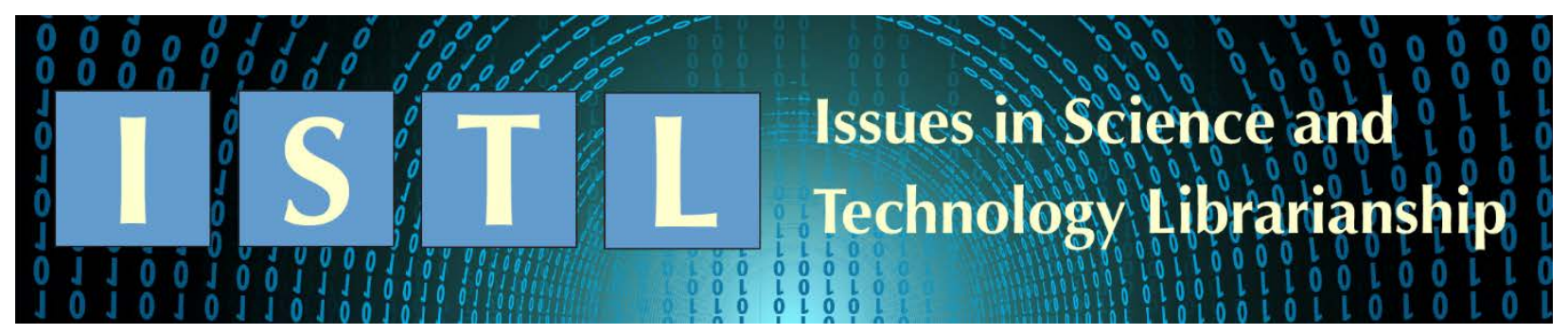

\title{
Agricultural Researchers' Attitudes Toward Open Access and Data Sharing
}

\author{
Sarah C. Williams \\ Head, Funk ACES Library \\ University of Illinois at Urbana-Champaign \\ Urbana, Illinois \\ scwillms@illinois.edu \\ Shannon L. Farrell \\ Natural Resources Librarian \\ University of Minnesota \\ Minneapolis, Minnesota \\ sfarrell@umn.edu \\ Erin E. Kerby \\ Veterinary Medicine \& Life Sciences Librarian \\ University of Illinois at Urbana-Champaign \\ ekerb@illinois.edu \\ Megan Kocher \\ Science Librarian \\ University of Minnesota \\ Minneapolis, Minnesota \\ mkocher@umn.edu
}

\begin{abstract}
This study involved a thorough examination of attitudes and opinions of agricultural researchers toward open access publishing and data sharing. Utilizing the results of the Ithaka $\mathrm{S}+\mathrm{R}$ Agriculture Research Support Services project, we reanalyzed our institutional interview transcripts and synthesized information from the project's publicly available reports. For comparison, we also searched and coded scientific and library literature. Our findings reveal common attitudes related to open access publishing and data sharing and point to potential roles for libraries to help address common impediments, such as lack of trust, time, and money. Overall, this study provides disciplinary context that can inform how librarians approach agricultural researchers about open access publishing and data sharing.
\end{abstract}




\section{Introduction}

The potential roles of agricultural librarians, and liaison librarians generally, continue to expand and may include providing instruction, managing collections, advising on scholarly communication issues, and consulting on research data challenges (Simonsen 2015). Ideally, liaison librarians approach these roles based on the culture and needs of the discipline (Gaines $\underline{2015}$ ). For agricultural librarians, the Ithaka S+R Agriculture Research Support Services project provided an opportunity to gather disciplinary practices and needs from researchers at multiple institutions.

Ithaka S+R, a not-for-profit research and consulting service for libraries and academia, organized the 2016-2017 agriculture project as part of its Research Support Services Program. The target population was active researchers aligned with the project's broad definition of agriculture (Cooper et al. 2017). University of Illinois at Urbana-Champaign and University of Minnesota were among the 19 U.S. research libraries that participated in the agriculture project, with all participants attending training and using the same semi-structured interview guide. The participants interviewed agricultural scholars at their institutions, coded interview transcripts, and wrote institutional reports. Most institutional reports are publicly available (USAIN n.d.) and some were published in a 2017 special issue of the Journal of Agricultural \& Food Information. Based on a sample of transcripts from all participating institutions, Ithaka $\mathrm{S}+\mathrm{R}$ also wrote an overarching project report (Cooper et al. 2017).

The Ithaka $S+R$ agriculture project generated a wealth of data that could not be fully discussed in the institutional reports or overarching report. For this study, we used the Ithaka $\mathrm{S}+\mathrm{R}$ results to more thoroughly explore two related topics that have been at the forefront of many science librarians' roles recently - open access and data sharing. Our goals were to identify common themes expressed by agricultural scholars regarding open access and data sharing; compare the themes to researcher perspectives available in the literature; analyze the open access and data sharing themes for similarities and differences; and suggest roles for libraries, especially to address impediments to open access publishing and data sharing. Ultimately, librarians can use this synthesized information to inform how they approach agricultural researchers about open access publishing and data sharing.

\section{Literature Review}

Many multidisciplinary studies have focused on researchers' attitudes, perceptions of, and behaviors with regard to open access. Many of these studies include very thorough literature reviews, and some are organized to uncover changes in attitudes and behaviors over time (Gaines 2015; Xia 2010). Xia (2010) went beyond providing an overview of changes to actually synthesizing results from earlier studies (with at least one representative publication for every year from 1991 through 2008) to reveal trends in attitude and changes in behavior of scholars. More recently, Gaines (2015) conducted a campus-wide survey at the University of Idaho to investigate faculty perceptions and knowledge of open access. This study, in which $28 \%$ of the respondents were from the College of Agricultural and Life Sciences, found disciplinary differences in faculty responses and concluded that these differences should inform how librarians approach faculty about open access. A more recent study by Rowley et al. (2017) found limited disciplinary differences in scholars' attitudes and behaviors, but revealed a high level of uncertainty about their future intentions toward publishing their research in open access journals. 
Studies focused on STEM disciplines are particularly relevant to our study of agricultural researchers. Fowler (2011) surveyed mathematicians worldwide on a variety of publishing issues, including open access, and found a strong opposition to open access fees. More recently, Cusker and Rauh (2014) surveyed physical sciences, engineering, and mathematics researchers (specifically excluding life scientists) to explore their experiences with and opinions of open access fees. They found some disciplinary differences, but most responses were negative, tentative, or uncertain.

With regard to data sharing, some multi-disciplinary studies have shown that researchers are increasingly making their data openly available, although this certainly does vary by discipline. Several large surveys conducted by the publisher Wiley in 2014 and 2016 provide some insight into global data sharing trends (Ferguson 2014; Vocile 2017). For example, 66\% of participants who identified as life scientists said they were sharing their data, usually as supplementary material in a journal (Ferguson 2014). These life science researchers said they would be even more likely to share data if they were assured of getting proper credit, which differed from those working in other disciplines who expressed concern for intellectual property and confidentiality. These results are similar to several institutional faculty surveys where reasons for sharing data, and reasons not to, varied considerably among disciplines (Akers \& Doty 2013; Buys \& Shaw 2015; Van Tuyl \& Michalek 2015). Researchers are clearly sharing their data, but as Borgman (2012) states, "The challenges are to understand which data might be shared, by whom, with whom, under what conditions, why, and to what effects."

Looking just at the sciences, Tenopir et al. (2011) found that while 85\% of their survey respondents were interested in using other researchers' datasets, $46 \%$ reported that they do not make their data electronically available to others. In a follow-up survey, Tenopir et al. (2015) found that while researcher engagement in data sharing had increased, there are continued and persistent challenges, such as proper attribution and concerns about misinterpretation and misuse of the data. A few studies looking specifically at life sciences researchers indicate that while data sharing does happen in this area, the researchers seem most comfortable sharing when directly asked by another researcher, as opposed to depositing in a repository or posting to a web site (Diekmann 2012; Herold 2015; Williams 2012). Those working in select areas though, genetics in particular, seem to be quite comfortable using repositories or submitting supplemental data files with articles (Williams 2012).

While there are many studies that explore open access publishing and many that explore data sharing, we found only two studies that discussed these two subjects in direct relation to each other. In a study looking at journal data policies and open access journals, Castro et al. (2017) found that $74 \%$ of the open access journals sampled did not have any data policy whatsoever, and only $6 \%$ required data sharing. The authors also found that commercial journals are at least as likely or more likely to have a data policy and often have stronger policies. They state, "There seems to be a stark contrast between the desire for openness of published results and the desire for openness of process and evidence." Within the context of a specific discipline, Teplitzky (2017) approached open access and data sharing from the opposite direction, looking at how many data sets in the Pangaea repository had corresponding journal articles available via open access. The author found that the incidence of publication in gold open access journals increased over time and many articles were available through more than one source. Since these articles explore open access and data sharing from different angles (i.e., journal policies and author behaviors), no conclusions can be drawn between them, but the limited literature indicates this is an area ripe for additional research. 


\section{Methods}

The Ithaka S+R Agriculture Research Support Services project outputs formed the basis of our study. We performed a qualitative analysis of the 28 Ithaka $S+R$ agriculture project interview transcripts from our two institutions (i.e., University of Illinois at Urbana-Champaign and University of Minnesota), the Ithaka S+R report (Cooper et al. 2017), and the publicly available institutional reports (USAIN n.d.). To comply with IRB guidelines, we only analyzed the interview transcripts from our own institutions (i.e., Illinois authors analyzed Illinois transcripts and Minnesota authors analyzed Minnesota transcripts) and shared anonymized notes with each other. Our approach to coding and analysis followed the training we received from Ithaka S+R on grounded theory, based on the work of Corbin and Strauss (2014). Grounded theory uses inductive reasoning, in which researchers start with qualitative data and review the data iteratively to assign codes and group the codes into concepts and categories. The goal is to develop new ideas and theories, rather than verify pre-existing theories. For our study, we extracted and coded data about open access and data sharing from our interview transcripts, the Ithaka $\mathrm{S}+\mathrm{R}$ summary report, and the publicly available institutional reports. We worked together to organize these codes into categories and identify major themes.

To contextualize our findings about agricultural researchers' attitudes on open access publishing and data sharing, we examined literature published in both the science and library science fields. Literature searches were performed in Scopus and Library \& Information Science Source for researchers' perspectives on both open access publishing and data sharing. This search resulted in various types of sources that included research articles, editorials, and commentaries. The findings of the research articles and the viewpoints of the editorials and commentaries were coded according to the themes we uncovered in the interviews.

\section{Results and Discussion}

From our coded data, major themes emerged. For both open access and data sharing, the researchers' comments were typically related to motivation and benefits and also concerns or barriers. Interestingly, the open access comments coalesced around two common benefits and two common concerns, while the benefits and barriers to data sharing were more varied. The major themes are summarized in Table 1.

\begin{tabular}{|c|c|c|c|}
\hline \multicolumn{4}{|c|}{ Table 1: Summary of Major Themes } \\
\hline & Open Access Publishing & Data Sharing & Common Themes \\
\hline $\begin{array}{l}\text { Motivations and } \\
\text { Benefits }\end{array}$ & $\begin{array}{l}\text { 1. Wide availability } \\
\text { 2. Good visibility }\end{array}$ & $\begin{array}{l}\text { 1. Wide availability } \\
\text { 2. Funder requirements } \\
\text { 3. Publisher requirements } \\
\text { 4. Transparency \& reproducibility } \\
\text { 5. Policy advancement }\end{array}$ & $\begin{array}{l}\text { 1. Wide availability } \\
\text { 2. Greater visibility }\end{array}$ \\
\hline Concerns/Barriers & $\begin{array}{ll}\text { 1. High fees } \\
\text { 2. Poor peer review/Low } \\
\text { quality }\end{array}$ & $\begin{array}{l}\text { 1. Data not valuable to others } \\
\text { 2. Difficult to prepare data to share } \\
\text { 3. Lack of reward } \\
\text { 4. Lack of time and/or knowledge } \\
\text { to share data } \\
\text { 5. Concerns about security, } \\
\text { privacy, and confidentiality } \\
\text { 6. Lack of trust }\end{array}$ & $\begin{array}{l}\text { 1. Lack of trust } \\
\text { 2. Limited time and } \\
\text { money } \\
\text { 3. Confusion and } \\
\text { misinformation }\end{array}$ \\
\hline
\end{tabular}




\section{Open Access}

The Ithaka S+R interviews only asked questions about open access in the context of depositing data or research products in a repository, but researchers at many institutions discussed open access much more broadly.

\section{Motivation and Benefits}

Our findings revealed two open access benefits commonly cited by researchers - wide availability and good visibility. Researchers pointed to a number of audiences that could benefit from the availability of open access articles. Research communities, especially collaborators and scientists in developing countries, are clear beneficiaries (Mills \& Giovenale 2016; Sheffield 2016; Stapleton et al. 2016). In some cases, researchers expressed an interest in open access publishing because the research would be available to practitioners, policymakers, and the public (Parker-Gibson \& Houpert 2016). One Minnesota researcher said, "I want anybody who wants to consume to consume it ... If you want this, go ahead, and if you want to slog through that kind of reading, go for it." Yet, other researchers noted that farmers and the public are often not equipped or interested to read complex, scientific articles (Rempel \& Robertshaw 2016). An Illinois researcher commented, "Well, most [farmers] aren't going to read your research paper. They want something that's more written in layman's terms."

It is notable that researchers were more interested in open access in terms of finding a broader audience for their work than in increasing their citation counts. Scientific and library literature have touted citation advantage as a selling point of open access publishing (Bernius 2010; DortaGonzález et al. 2017; Joint 2009; Lawrence 2001; Nelson \& Eggett 2017; Rowley et al. 2017; Tang et al. 2017; Teplitzky \& Phillips 2016; Woszczynski \& Whitman 2016), even though some studies have found that this effect is sometimes weak or nonexistent (Flaxbart 2008; Gaule \& Maystre 2008; Salisbury et al. 2017). Based on these survey responses, it would seem that focusing more on broader reach generally rather than citation advantage specifically may be a message that resonates with agricultural researchers.

The wide availability of open access articles could be a particularly strong motivating factor for agricultural researchers at land-grant institutions, given their mission to communicate research results to citizens. Multiple Illinois interviewees expressed a commitment to this land-grant mission, such as one who said, "[the institution] was founded to give a neutral, independent, objective source of information that would benefit the public." While these statements were not necessarily made in reference to open access, an agricultural researcher with this commitment might be receptive to and interested in open access publishing. This echoes the perspectives of researchers across the sciences who are committed to open access as public good through means of furthering social justice (Arunachalam 2017), providing a return on taxpayers' investments in research (Björk 2017; Nelson \& Eggett 2017), and extending the benefits of research findings to a global audience (Bolick et al. 2017; $\underline{\text { Smith et al. 2017). }}$.

While perhaps less altruistic, good visibility was the other commonly cited benefit of open access. This is especially true of high-profile open access journals, such as PLOS ONE, BMC Genome Biology and eLife that were specifically mentioned by Illinois researchers, including one who said, "I'd still consider publishing in those sort of high prestige open access [journals] because I think they get a lot of visibility in their citations." For some researchers, the good visibility of open access publications is enough to offset their high cost (McManus et al. 2017). 


\section{Concerns}

Our findings also revealed two concerns commonly mentioned by agricultural researchers regarding open access - high fees and poor peer review/low quality - which echo concerns expressed by scientists in other disciplines (Cusker \& Rauh 2014; Gaines 2015). Many interviewees expressed an inability to pay for open access rather than unwillingness to pay (Cooper et al. 2017). In contrast, a study of mathematicians' attitudes found twice as many respondents were unwilling to pay open access than were unable to pay (Fowler 2011). One agricultural researcher who makes a point of publishing open access tempered that by saying, "when I can afford it" (McManus et al. 2017). An Illinois interviewee described in detail how open access fees changed the lab's publishing practices over time. At one time, open access publications and hybrid open access journals had comparable fees, so the lab typically published in open access publications, but more recently, "the fees for some of these [open access] journals are getting outrageous," so the lab is going back to traditional subscription journals because their open access fees are cheaper. In a recent study of 168 hybrid open access agricultural journals, only $4.7 \%$ of 46,373 research articles were open access (Kocher \& Kelly 2016), so this shift to hybrid open access mentioned by the interviewee does not appear to be widespread among agricultural researchers.

Some agricultural researchers do find funding to support open access, but there are limitations. One Minnesota researcher relies on Hatch Act funding or other grant funding and indicated that this is somewhat common practice - "typically when I write a grant proposal I'll include a publication piece in the budget. Actually a lot of us do that and that, you know, it might cost $\$ 1500$ or something like that to publish [in] an open access journal. So you want to get two or three of those so you build that into the budget." Yet, other interviewees from Minnesota and Illinois expressed concerns about balancing research costs and publication costs in grant proposals, like one who said, "when you're looking at very tight grant budgets, you want to hire the people who are going to do the research. Oftentimes you cut short the computer cost and the publication costs because you don't want to trim the budget too much from what you need for your expendables and your labor." An Illinois interviewee noted that grants received for agricultural research are typically not big enough to support large open access expenses. At some institutions, library support for open access fees is another option, but this certainly is not universal. One Minnesota researcher, who had published in an open access journal once, specifically mentioned the library had provided funds to cover a third of the $\$ 3000$ open access fee.

Poor peer review or low quality of open access journals is a concern of many agricultural researchers (Delserone \& Dinkelman 2016; Parker-Gibson \& Houpert 2016; Rempel \& Robertshaw 2016; Sheffield 2016). This concern is often mixed with uncertainty. As one Illinois interviewee expressed, "Are they really of the same quality and standard? ... There are some that are okay and there's some that are maybe not so okay ... I'm not sure which ones are which." Another Illinois interviewee, who had been a self-described "big open access enthusiast," articulated a waning enthusiasm as the quality of open access publications has decreased. In particular, this interviewee said, "I'm nervous about my students publishing their thesis in [open access publications] and then in five or ten years, that publication on their CV doesn't look like much," which seems to be a rather unique perspective on this common concern about low quality. Fears of low quality publications and predatory publishers have also been noted in other fields of science, with particular concerns around credit towards promotion and tenure (Björk 2017; Mann et al. 2009; Woszczynski \& Whitman 2016). 


\section{Potential Library Roles}

These common concerns point to potential roles for libraries in the open access movement. Researchers experience uncertainty on multiple levels. In addition to their uncertainty about the quality of open access publications, they express uncertainty about their future intentions regarding open access publishing (Rowley et al. 2017), and at the most basic level, some do not fully understand open access and mistake journals that they can access due to their libraries' subscriptions for open access journals (Fowler 2011; Rowlands \& Nicholas 2005). The high level of uncertainty surrounding open access is an opportunity for libraries to provide education and guidance, which echoes recommendations from some Ithaka S+R institutional reports (Delserone \& Dinkelman 2016; Mills \& Giovenale 2016; Sheffield 2016), and the findings in this study can inform how librarians approach agricultural researchers about open access. As librarians, it is important for us to consider our approaches to outreach involving open access and frame it in ways that are tailored to our audiences as suggested by Gaines (2015) and Otto (2016). To speak to the interests and concerns of agricultural researchers, education and guidance could focus on what open access is; how it can make research more widely available, especially to researchers in developing countries, citizens, and policymakers; and how to identify high-quality open access publications with strong peer review.

Since cost is another major barrier, libraries could also play a role by providing funds to support open access publishing, although this comes with challenges. At some institutions with open access funds, libraries need to increase promotion of the funds so researchers are more aware of their availability (McManus et al. 2017; Sheffield 2016). At Minnesota, on the other hand, the open access fund was being depleted so quickly that additional limitations were established when the fund was reviewed in 2016; in particular, support was removed for hybrid open access publication fees that had previously been supported up to a 50\% maximum of $\$ 2000$ (University of Minnesota 2017). Beaubien et al. (2016) found that covering costs for hybrid publications allowed researchers to make their work open access without publishing in unknown or lesstrusted publications, but had hopes to use this to push users of the fund toward publishing in fully open access publications. Librarians at institutions with existing open access funds should certainly promote these funds to agricultural researchers since more express an inability, rather than an unwillingness, to pay open access fees (Cooper et al. 2017). An evaluation of the open access fund at UC Berkeley (Teplitzky \& Phillips 2016) found that the College of Natural Resources, which includes agriculture, was the largest user of that institution's fund. At institutions with no open access funds, librarians could advocate to library and campus administrators for the value of such funds to agricultural researchers or explore funding options that might be more within their control, such as endowment funds that could support open access fees.

\section{Data Sharing}

Although only one interview question asked about sharing research data, participants responded with a wide range of opinions, experiences, and understanding of the issues. While one institution reported that their interviewees were aware of the increasing trend in depositing data (Parker-Gibson \& Houpert 2016), others reported that their interviewees were uncertain about data sharing requirements and the best strategy for sharing. In general, the interviewees in this study discussed a number of different benefits to sharing data, but also expressed some concerns and explained the barriers they had come up against. Agricultural researchers appear to have quite a pragmatic view of data sharing as far as their actual practices, yet there is evidence that they are also concerned with the common good. 


\section{Motivation and Benefits}

Of those participants who said they had deposited data in a repository, the primary motivations were to make data available for others to use, to meet funding agency requirements, and to meet publisher requirements (Cooper et al. 2017). These findings support the idea that the motivations for sharing data are often a blend of individual choice and institutional policy as discussed by Tenopir et al. (2011). Numerous studies by librarians and scientists have shown that funding and publisher requirements are primary reasons that researchers share their data (Kim \& Kim 2015; Kim \& Stanton 2016; Thelwall \& Kousha 2017; Williams 2013). Nonetheless, there seems to be a growing belief that, where possible, data should be shared because it benefits the community. One Minnesota researcher, for example, commented "The motivation largely is because it's a requirement of funding agencies and publications, but probably we do it anyway because it's good practice, and we want the data to be out there and accessible and useful for others."

Several researchers, from both Minnesota and Illinois, explained that they were currently working on a grant that would require them to deposit data in a repository and that it would be their first time doing so. One admitted that they have not shared data before because they had never been required to and because it takes additional time. Interestingly, another Minnesota researcher commented that they had never deposited data until required, but the experience convinced them what a great idea depositing data is because it makes the data easier to find. The interviewee comments reflect the findings of Thelwall and Kousha (2017), who found data sharing mandates are highly effective technically at getting researchers to share their data, with the best-case scenario being that it convinces researchers that sharing data is simply good practice.

While data sharing often hinges on individual choice, many agricultural researchers see clear benefits to data sharing. Several study participants from Minnesota stated that depositing data in a repository promotes transparency and reproducibility of the research, as it provides a record of the data. This type of formal data sharing also helps with discovery and attribution by making the data more easily accessible, even if only in the form of a supplementary file on the journal web site. Some participants talked about data sharing helping other researchers and being "for the common good." Many of them have used data shared by another researcher and feel that they should do the same for others. There even seems to be an expectation by the agricultural research community that researchers will share data, particularly those working in genetics. Although only one researcher from Minnesota mentioned it, data sharing can also have the benefit of influencing policy by informing debate and thereby improving the decision making of stakeholders. These responses are not surprising, given that scholarly altruism has been shown to be a motivating factor for scientists sharing data across multiple other surveys (Kim \& Stanton 2016; Luzi et al. 2013; Williams 2013). Upholding the principles of transparency, reuse, and verification also seem to strike a chord in the sciences and may be concepts for librarians to explore in further promoting data sharing to agricultural researchers (Gezelter 2015; Hudson 2016; Keil 2014).

It is interesting to note that one advantage of data sharing not mentioned by participants in the Ithaka S+R study was the citation advantage. Although multiple studies have found some evidence of correlation between shared data and higher citation counts, it either did not occur to the researchers in this study that this was a possibility, or this is not a major motivating factor for them (Drachen et al. 2016; Piwowar \& Vision 2013; Thelwall \& Kousha 2017). Another benefit not cited by the agricultural researchers in the Ithaka S+R study is the ability to make "negative" or otherwise unpublished data available, although it has been noted by other scientists (Keil 
2014; Leonelli et al. 2013). For librarians, both of these advantages could be explored with agricultural researchers to determine whether they are motivators.

\section{Barriers}

While recognizing the benefits of sharing data, agricultural researchers have come up against considerable barriers to data sharing with no clear-cut path around them. Participants in the Ithaka S+R study gave the following reasons for not sharing their data: the data would not be meaningful to others, the data would be difficult to prepare for sharing, a focus on publication rather than data sharing, and lack of reward (Cooper et al. 2017). At this point in time, agricultural researchers typically do not receive any reward or recognition in terms of promotion and tenure for sharing their data. Consequently, several study participants said that it then becomes a matter of whether or not they are required to share data. This relates to the findings of Schmidt et al. (2016) that "loss of credit or recognition" when one's data is used by another researcher is one of the primary barriers to sharing data generally in the sciences.

Another barrier to data sharing is the amount of time and knowledge necessary. While some librarians have advocated for incorporating data sharing into the research process, several of the study participants said that there often is just not enough time in the day for them to do so. Time as a barrier to data sharing has been well-documented across many disciplines (Douglass et al. 2014; Kim \& Stanton 2016; Williams 2013). Akers \& Doty (2012) suggested that there might be a rank divide in that senior-ranking faculty more often cite time and organization as barriers to sharing, whereas junior faculty were more likely to see data sharing as a part of their research process rather than "extra" time spent. There is insufficient data to know if this holds true for the researchers in the Ithaka S+R study. Furthermore, some researchers feel that if their skills are lacking, there is not enough time to learn how to share their data. One Minnesota researcher stated, "...it would mean a massive restructuring of how we currently handle the data to be able to do that [share data]. And we barely have time to get data collected, analyzed, get published, without revising it." This problem with lack of time and knowledge might be due in part to a distinct lack of standards for data sharing in many areas of agricultural research. Without standards, it can be difficult to integrate data sharing into the research process and to develop best practices. The researchers are left to share their data in inconsistent ways, with varying levels of access, description, metadata, etc. This is in line with the findings of other studies (Akers \& Doty 2012; Luzi et al. 2013; Sayogo \& Pardo 2013) and suggests that librarians could assist researchers more by finding ways to streamline, demystify, and standardize the data sharing process.

Security, privacy, confidentiality, access control, and a general lack of trust in sharing data all came up repeatedly throughout the interviews. For some, these concerns were due to the type of research they conduct. For one Illinois researcher working with human subjects data, confidentiality is critical; "...in fact, everything that we do today is backed up by a confidentiality agreement." For others, these concerns stemmed from a lack of confidence in the current data sharing infrastructures and standards. As one Minnesota researcher put it, "Any hacker can find the data set and unscrupulously just reanalyze and publish it as their own thing and nobody's going to have the time or inclination or capabilities to even do the data sniffing to say 'hey, that was fraudulent."' These concerns align with those found by Schmidt et al. (2016) that across the sciences, researchers worry that sharing their data will jeopardize their ability to publish on it and/or control how it is used. 


\section{Potential Library Roles}

One clear role for the library when it comes to data sharing is the provision and management of institutional repositories, whether it is a general repository or a dedicated data repository. Particularly in areas of agricultural research where there is not an established repository, libraries and institutional repositories can alleviate some of the lack of trust and access control issues that some researchers appear to have. It was clear that many of the participants in the Ithaka S+R study view the library as a trustworthy entity, and one Illinois researcher even stated that they would be more comfortable depositing data with the library.

Providing one-on-one consultation to researchers needing to select a repository and prepare their data could serve to alleviate the aforementioned issues with the lack of time and knowledge. In addition to providing more practical or functional services, there clearly is an educational role for libraries when it comes to data sharing. As Bishoff \& Johnston (2015) found, researchers need more education on the basic mechanics and definitions of data sharing. The interviews provided evidence that there are misconceptions about what it means to share data; some researchers appear to conflate data sharing with big data, which are two distinct concepts. One outreach strategy that could be further explored in the agricultural sciences is using data sharing requirements from individual journals as a means to get interest from specific users or departments (Fear 2015).

\section{Themes Across Open Access and Data Sharing}

Several themes emerged across discussions of open access and data sharing that give insight into the common priorities and concerns of agricultural researchers. In terms of motivation, a recurrent theme was altruism - sharing data or publishing in open access journals for the benefit of others. Both open access and data sharing are tied to the land grant mission and local and global outreach, with particular concern for sharing with scientists in the developing world who might not have ready access to scholarship and data otherwise. Secondary to altruism, but important nonetheless, is that agricultural researchers share data and publish in open access journals to increase the visibility of their work in the interest of their own careers, be that toward promotion and tenure, increasing their citation counts, or adding transparency to their research process.

In terms of barriers, several commonalities can also be seen. Trust is a major impediment for both data sharing and open access publishing. We saw that researchers were concerned about predatory publishers of open access journals, as well as the potential for nefarious uses of their hard-earned data if it were shared broadly. Another difficulty that is certainly not unique to agricultural researchers is the tight allocation of time and money. If researchers are going to put these types of resources towards cleaning up their data or paying open access fees, they need to be assured that it is a worthwhile investment. Researchers also care about prestige. They want to make sure that the journals they publish in have solid, established reputations and they want to get credit if others use their data sets.

Confusion and misinformation were also common themes. Researchers interviewed in this study expressed a range of knowledge about what constitutes open access publishing and data sharing. Based on these findings, we can surmise that there is still a good deal of work to be done in educating researchers and embedding open access and data sharing into the culture of agricultural research. 


\section{Conclusion}

Understanding the balance of the pressures and priorities of agricultural researchers can help librarians in developing and promoting services around open access publishing and data sharing. As we have noted, much research in both of these areas focuses on citation advantage. This addresses some concerns about prestige and career advancement, but these interviews show that researchers care about more. Making direct links to the values of researchers in terms of sharing their research with the public and increasing the reproducibility and transparency of their research would appear to resonate with researchers. In addition, librarians can assist researchers by vetting journals and data repositories to ensure that they meet researchers' expectations for trustworthiness. Finally, librarians need to address why these are worthwhile investments of time and money and do what they can to ease these burdens on already overtaxed researchers.

\section{References}

Akers, K.G. \& Doty, J. 2012. Differences among faculty ranks in views on research data management. IASSIST Quarterly 36(2): 16-20. Available from https://iassistdata.org/sites/default/files/iqvol36_2_doty.pdf

Akers, K.G. \& Doty, J. 2013. Disciplinary differences in faculty research data management practices and perspectives. International Journal of Digital Curation 8(2): 5-26. DOI: $\underline{10.2218 / i j d c . v 8 i 2.263}$

Arunachalam, S. 2017. Social justice in scholarly publishing: open access is the only way. The American Journal of Bioethics 17(10): 15-17. DOI: 10.1080/15265161.2017.1366194

Beaubien, S., Garrison, J. \& Way, D. 2016. Evaluating an open access publishing fund at a comprehensive university. Journal of Librarianship and Scholarly Communication 3(3): 1-12. DOI: $\underline{10.7710 / 2162-3309.1204}$

Bernius, S. 2010. The impact of open access on the management of scientific knowledge. Online Information Review 34(4): 583-603. DOI: 10.1108/14684521011072990

Bishoff, C. \& Johnston, L. 2015. Approaches to data sharing: an analysis of NSF data management plans from a large research university. Journal of Librarianship and Scholarly Communication 3(2): 1-27. DOI: 10.7710/2162-3309.1231

Björk, B-C. 2017. Open access to scientific articles: a review of benefits and challenges. Internal and Emergency Medicine 12(2): 247-253. DOI: 10.1007/s11739-017-1603-2

Bolick, J., Emmett, A., Greenberg, M.L., Rosenblum, B. \& Peterson, A.T. 2017. How open access is crucial to the future of science: open access. The Journal of Wildlife Management 81(4): 564-566. DOI: $\underline{10.1002 / j w m g .21216 ~}$

Borgman, C.L. 2012. The conundrum of sharing research data. Journal of the American Society for Information Science and Technology 63(6): 1059-1078. DOI: 10.1002/asi.22634 
Buys, C.M. \& Shaw, P.L. 2015. Data management practices across an institution: survey and report. Journal of Librarianship and Scholarly Communication 3(2): 1-24. DOI: 10.7710/2162$\underline{3309.1225}$

Castro, E., Crosas, M., Garnett, A., Sheridan, K. \& Altman, M. 2017. Evaluating and promoting open data practices in open access journals. Journal of Scholarly Publishing 49(1): 66-88. DOI: $\underline{10.3138 / j s p .49 .1 .66}$

Cooper, D., et al. 2017. Supporting the Changing Research Practices of Agriculture Scholars. DOI: $\underline{10.18665 / \text { sr.303663 }}$

Corbin, J. \& Strauss, A. 2014. Basics of Qualitative Research: Techniques and Procedures for Developing Grounded Theory. Los Angeles: SAGE Publications.

Cusker, J. \& Rauh, A.E. 2014. A survey of physical sciences, engineering and mathematics faculty regarding author fees in open access journals. Issues in Science and Technology Librarianship 78. DOI: 10.5062/F4VH5KTQ

Delserone, L.M. \& Dinkelman, A.L. 2016. Investigating the practices and needs of agricultural researchers at the University of Nebraska-Lincoln. Available from:

http://digitalcommons.unl.edu/libraryscience/341/

Diekmann, F. 2012. Data practices of agricultural scientists: results from an exploratory study. Journal of Agricultural \& Food Information 13(1): 14-34. DOI: 10.1080/10496505.2012.636005

Dorta-González, P., González-Betancor, S.M. \& Dorta-González, M.I. 2017. Reconsidering the gold open access citation advantage postulate in a multidisciplinary context: an analysis of the subject categories in the Web of Science database 2009-2014. Scientometrics 112(2): 877901. DOI: $10.1007 / \mathrm{s} 11192-017-2422-\mathrm{y}$

Douglass, K., Allard, S., Tenopir, C., Wu, L. \& Frame, M. 2014. Managing scientific data as public assets: data sharing practices and policies among full-time government employees. Journal of the Association for Information Science \& Technology 65(2): 251-262. DOI: $\underline{10.1002 / a s i .22988}$

Drachen, T.M., Ellegaard, O., Larsen, A.V. \& Dorch, S.B.F. 2016. Sharing data increases citations. Liber Quarterly: The Journal of European Research Libraries 26(3): 67-82. DOI: $\underline{10.18352 / l q .10149}$

Fear, K. 2015. Building outreach on assessment: researcher compliance with journal policies for data sharing. Bulletin of the Association for Information Science \& Technology 41(6): 18-21. DOI: $10.1002 /$ bult.2015.1720410609

Ferguson, L. 2014. How and why researchers share data (and why they don't). The Wiley Network: Discover the Future of Research [Internet]. [accessed 2018 Mar 2]. Available from: https://hub.wiley.com/community/exchanges/discover/blog/2014/11/03/how-and-whyresearchers-share-data-and-why-they-dont

Flaxbart, D. 2008. On impact of OA, the jury is still out. Issues in Science \& Technology Librarianship 54. DOI: 10.5062/F4DF6P53 
Fowler, K.K. 2011. Mathematicians' views on current publishing issues: A survey of researchers. Issues in Science and Technology Librarianship 67. DOI: 10.5062/F4QN64NM

Gaines, A.M. 2015. From concerned to cautiously optimistic: assessing faculty perceptions and knowledge of open access in a campus-wide study. Journal of Librarianship and Scholarly Communication. 3(1), p.eP1212. DOI: $\underline{\text { 10.7710/2162-3309.1212 }}$

Gaule, P. \& Maystre, N. 2008. Getting cited: does open access help? Available from: http://www.aeaweb.org/aea/conference/program/retrieve.php?pdfid=147

Gezelter, J.D. 2015. Open source and open data should be standard practices. The Journal of Physical Chemistry Letters 6(7): 1168-1169. DOI: 10.1021/acs.jpclett.5b00285

Herold, P. 2015. Data sharing among ecology, evolution, and natural resources scientists: an analysis of selected publications. Journal of Librarianship and Scholarly Communication 3(2): 1-23. DOI: $\underline{10.7710 / 2162-3309.1244}$

Hudson, M.A. 2016. Data sharing - peeping inside Pandora's box. European Science Editing 42(4): 91-93. DOI: 10.20316/ESE.2016.42.021

Joint, N. 2009. The Antaeus column: does the "open access" advantage exist? a librarian's perspective. Library Review 58(7): 477-481. DOI: 10.1108/00242530910978172

Keil, D.E. 2014. Research data needs from academic libraries: the perspective of a faculty researcher. Journal of Library Administration 54(3): 233-240. DOI: $\underline{10.1080 / 01930826.2014 .915168}$

Kim, Y. \& Kim, S. 2015. Institutional, motivational, and resource factors influencing health scientists' data-sharing behaviours. Journal of Scholarly Publishing 46(4): 366389. DOI: 10.3138/jsp.46.4.05

Kim, Y. \& Stanton, J.M. 2016. Institutional and individual factors affecting scientists' datasharing behaviors: a multilevel analysis. Journal of the Association for Information Science \& Technology 67(4): 776-799. DOI: 10.1002/asi.23424

Kocher, M. \& Kelly, J. 2016. Use of paid open access option in hybrid open access journals in agriculture: a mixed-methods study. Issues in Science and Technology Librarianship 85. DOI: 10.5062/F47P8WDB

Lawrence, S. 2001. Free online availability substantially increases a paper's impact. Nature 411: 521. DOI: $10.1038 / 35079151$

Leonelli, S., Smirnoff, N., Moore, J., Cook, C. \& Bastow, R. 2013. Making open data work for plant scientists. Journal of Experimental Botany 64(14): 4109-4117. DOI: 10.1093/jxb/ert273

Luzi, D., Ruggieri, R., Biagioni, S. \& Schiano, E. 2013. Data sharing in environmental sciences: a survey of CNR researchers. Grey Journal (TGJ) 9(2): 69-81. Available from http://www.greynet.org/images/GL14-S2P,_Luzi_et_al.pdf 
Mann, F., von Walter, B., Hess, T. \& Wigand, R.T. 2009. Open access publishing in science. Communications of the ACM 52(3): 135. DOI: 10.1145/1467247.1467279

McManus, A., Callahan, B. \& Glennie, C. 2017. Research support services: agriculture. Available from http://escholarship.org/uc/item/7qr1h8ws

Mills, C.V. \& Giovenale, S. 2016. Research support study: agriculture; University of Connecticut local report. Available from http://opencommons.uconn.edu/libr_pubs/57/

Nelson, G.M. \& Eggett, D.L. 2017. Citations, mandates, and money: author motivations to publish in chemistry hybrid open access journals. Journal of the Association for Information Science and Technology 68(10): 2501-2510. DOI: 10.1002/asi.23897

Otto, J.J. 2016. A resonant message: aligning scholar values and open access objectives in OA policy outreach to faculty and graduate students. Journal of Librarianship and Scholarly Communication 4: 1-34. DOI: 10.7710/2162-3309.2152

Parker-Gibson, N.T. \& Houpert, M.U. 2016. Research support services for the field of agriculture: semi-structured interviews. Available from:

http://uark.libguides.com/c.php?g=589516

Piwowar, H.A. \& Vision, T.J. 2013. Data reuse and the open data citation advantage. PeerJ 1, e175. DOI: $\underline{10.7717 / \text { peerj.175 }}$

Rempel, H.G. \& Robertshaw, M.B. 2016. Supporting the research practices of agricultural scientists: Oregon State University's Ithaka report. Available from:

http://ir.library.oregonstate.edu/concern/technical_reports/5q47rt35v

Rowlands, I. \& Nicholas, D. 2005. Scholarly communication in the digital environment: the 2005 survey of journal author behaviour and attitudes. Aslib Proceedings 57(6): 481-497. DOI: $\underline{10.1108 / 00012530510634226}$

Rowley, J., Johnson, F., Sbaffi, L., Frass, W. \& Devine, E. 2017. Academics' behaviors and attitudes towards open access publishing in scholarly journals. Journal of the Association for Information Science and Technology 68(5): 1201-1211. DOI: $10.1002 / a s i .23710$

Salisbury, L., Chowdhury A.R. \& Smith, J.J. 2017. Faculty publications from a research university: the scholarly impact of open access versus non-open access. Science \& Technology Libraries 36(2): 187-199. DOI: 10.1080/0194262X.2016.1273815

Sayogo, D.S. \& Pardo, T.A. 2013. Exploring the determinants of scientific data sharing: understanding the motivation to publish research data. Government Information Quarterly 30(1): S19-S31. DOI: 10.1016/j.giq.2012.06.011

Schmidt, B., Gemeinholzer, B., \& Treloar, A. 2016. Open data in global environmental research: the Belmont Forum's open data survey. PLOS ONE 11(1): e0146695. DOI: 10.1371/journal.pone.0146695

Sheffield, M. 2016. Research support services in agriculture. Available from: http://tigerprints.clemson.edu/lib_pubs/131/ 
Simonsen, J.E. 2015. The liaison's role in serving agriculture and life sciences information users: a review of the literature. Journal of Agricultural \& Food Information 16(1): 11-30. DOI: $\underline{10.1080 / 10496505.2014 .982753}$

Smith, E., Haustein, S., Mongeon, P., Shu, F., Ridde, V. \& Lariviere, V. 2017. Knowledge sharing in global health research - the impact, uptake and cost of open access to scholarly literature. Health Research Policy and Systems 15(1). DOI: 10.1186/s12961-017-0235-3

Stapleton, S., Minson, V. \& Spears, L. 2016. Research support services: agricultural sciences. Available from: http://ufdc.ufl.edu/IR00009135/00001

Tang, M., Bever, J.D. \& Yu, F-H. 2017. Open access increases citations of papers in ecology. Ecosphere 8(7): e01887. DOI: 10.1002/ecs2.1887

Tenopir, C., Allard, S., Douglass, K., Aydinoglu, A.U., Wu, L., Read, E., ... Frame, M. 2011. Data sharing by scientists: practices and perceptions. PLOS ONE 6(6). DOI: 10.1371/journal.pone.0021101

Tenopir, C., Dalton, E.D., Allard, S., Frame, M., Pjesivac, I., Birch, B., ... Dorsett, K. 2015. Changes in data sharing and data reuse practices and perceptions among scientists worldwide. PLOS ONE 10(8). DOI: 10.1371/journal.pone.0134826

Teplitzky, S. 2017. Open data, [open] access: linking data sharing and article sharing in the earth sciences. Journal of Librarianship and Scholarly Communication 5: 1-16. DOI: 10.7710/2162$\underline{3309.2150}$

Teplitzky, S. \& Phillips, M. 2016. Evaluating the impact of open access at Berkeley: results from the 2015 survey of Berkeley Research Impact Initiative (BRII) funding recipients. College \& Research Libraries 77(5): 568-581. DOI: 10.5860/crl.77.5.568

Thelwall, M., \& Kousha, K. 2017. Do journal data sharing mandates work? life sciences evidence from Dryad. Aslib Journal of Information Management 69(1): 36-45. DOI: 10.1108/AJIM-09-2016-0159

University of Minnesota. 2017. Details/History of the Fund [Internet]. [accessed 2017 Dec 21]. Available from https://www.lib.umn.edu/openaccess/details-fund

USAIN. n.d. USAIN Members Investigate the Needs of Agriculture Scholars [Internet]. [accessed 2018 Feb 15]. Available from https://usain.org/Ithaka-S+R

Van Tuyl, S. \& Michalek, G. 2015. Assessing research data management practices of faculty at Carnegie Mellon University. Journal of Librarianship and Scholarly Communication 3(3). DOI: $\underline{10.7710 / 2162-3309.1258}$

Vocile, B. 2017. Open science trends you need to know about. The Wiley Network: Discover the Future of Research [Internet]. [accessed 2018 Mar 2]. Available from: https://hub.wiley.com/community/exchanges/discover/blog/2017/04/19/open-science-trends-youneed-to-know-about 
Williams, S.C. 2012. Data practices in the crop sciences: a review of selected faculty publications. Journal of Agricultural \& Food Information 13(4): 308-325. DOI:

$\underline{10.1080 / 10496505.2012 .717846}$

Williams, S.C. 2013. Data sharing interviews with crop sciences faculty: why they share data and how the library can help. Issues in Science and Technology Librarianship 72. DOI:

10.5062/F4T151M8

Woszczynski, A.B. \& Whitman, M.E. 2016. Perspectives on open access opportunities for IS research publication: potential benefits for researchers, educators, and students. Journal of Information Systems Education 27(4): 259-276. Available from http://jise.org/Volume27/n4/JISEv27n4p259.pdf

Xia, J. 2010. A longitudinal study of scholars attitudes and behaviors toward open-access journal publishing. Journal of the American Society for Information Science and Technology 61(3): 615624. DOI: $10.1002 /$ asi.21283 